\title{
Assessment of the Nutrition and Dietary Status During Pregnancy
}

\author{
Hassan S. O. Abduljabbar*, Abdullah K. Agabawi, Maryam H. Habib, Sondos Alturkistani, \\ Bashair Azhari
}

Department of Obstetrics \& Gynecology, Medical College, King Abdulaziz University, Jeddah, Saudi Arabia

\section{Email address:}

profaj17@yahoo.com (H. S. O. Abduljabbar)

${ }^{*}$ Corresponding author

\section{To cite this article:}

Hassan S. O. Abduljabbar, Abdullah K. Agabawi, Maryam H. Habib, Sondos Alturkistani, Bashair Azhari. Assessment of the Nutrition and Dietary Status During Pregnancy. International Journal of Nutrition and Food Sciences. Vol. 6, No. 1, 2017, pp. 25-30. doi: $10.11648 /$ j.ijnfs.20170601.15

Received: November 26, 2016; Accepted: December 19, 2016; Published: January 18, 2017

\begin{abstract}
The Objective of the study Is to assess the nutrition during pregnancy in Saudi women. It is a cross-sectional descriptive study conducted to collect, describe and analyze the nutritional status during pregnancy, performed on pregnant women.(May 2016 - July 2016). (210) patients selected from the antenatal clinic KAUH. Inclusion criteria include pregnant women, not in a special diet, and willing to participate. The ethics committee of KAU approved the study. Data collected using a Questionnaire (Food Frequency Questionnaire) developed and validated in English language. The questionnaire proposed, used as an indicator of a healthy nutritional diet. Which include eight questions. Results; The total number questionnaires (187) were ready for analysis the positive response rate was only (89.1\%). The mean \pm stander deviation of age (28.79 \pm 5.418$)$, Gravidity $(2.98 \pm 2.180)$, Gestational Age $(29.42 \pm 7.920)$. The mean of hemoglobin $(9.79 \pm 1.49)$, and BMI range from $14-$ 45 with a mean of $(27.33 \pm 6.59)$. When analyzing the questionnaires pregnant women divided into two group. Group 1 (171) those women who consumes healthy diet (eight questions answered yes) and Group 2 only 16 pregnant women out 187 $(8.56 \%)$ consumes a poor diet. $(25.7 \%)$ had hemoglobin was less than $9 \mathrm{mg} / \mathrm{dL}$. The group the poor diet had more small baby which was statistically significant with $\mathrm{P}<0.026$. Comparing the two groups the fetal complication were statistically significant higher in the poor diet group, with a $p$ value $<0.004$ with OD ratio $95 \%$ confidence limit $7.318(2.128-25.166)$. The level of hemoglobin were less than $10 \mathrm{mg} / \mathrm{dL} 0.280(0.087-0.902) \mathrm{P}<0.022$. The MBI less than 25 with ODs ratio and $95 \% \mathrm{cl}$ $0.364(0.121-1.092)$ and $p<0.54$. In conclusion, our sample of Saudi pregnant women only $8.56 \%$, and $25.7 \%$ their hemoglobin were less than $9 \mathrm{gm} / \mathrm{dL}$ and their BMI were 27. 33. Poor diet affect only the level of hemoglobin and fetal weight at delivery.
\end{abstract}

Keywords: Nutrition, Pregnancy, Saudi Arabia

\section{Introduction}

Pregnancy considered a critical stage of life for both mother and fetus. It needs attention in term of health, exercise and nutrition. [1]. Women's nutrition is a major public health issue, it involve nutrition for Adolescents, preconception and women during pregnancy and lactations. [2]. It has a tremendous effect on women health as well as the health of the Future generations. Nutritional status has an influence on reproductive status such as age at menarche, fetal growth and birth weight, women's ability to go through health pregnancy and save lactation Malnutrition in pregnancy impairs the mothers owns health and has an ill effect on the newborn. [3]. Not only adequate nutrition is essential for fetal development but also a balanced nutrition intake in the diet of the women before and during pregnancy has a significant implication for the baby birth weight, fetal programming of non-communicable diseases and their response to subsequent illness. [4]. The aim is assessment of the nutritional status of Saudi pregnant women. 


\section{Materials and Methods}

A cross-sectional descriptive study conducted to collect, describe and analyze the nutritional status during pregnancy. The survey performed on volunteer's pregnant women. From May 23, 2016, to July 28, 2016, (210) patients selected from the outpatient's antenatal clinic at King Abdulaziz University Hospital.

All participants of the study signed an informed consent. Inclusion criteria include pregnant women, not in a special diet, and willing to participate. The ethics committee of KAU approved the study. Data collected using a Questionnaire (Food Frequency Questionnaire) - which is a simple, brief that administered through an interview, which was originally developed and validated in English language. Consist of age in years, Gravidity, Gestational Age in weeks, history of taking any supplement, Educational Status, Past Medical, Surgical and Social History. (Height, Weight, BMI) Hemoglobin and fetal weight, fetal and maternal complications. Data after follow up and delivery recorded from the medical chart.

To determine the frequency of consumption of different types of categories of Saudi diet, which collected from pregnant women by (Food Frequency Questionnaire). The assessment method is to determine the frequency and not the portion size by describing all foods and beverages consumed in the past 24 hours to a week.

The questionnaire proposed, used as an indicator of a healthy nutritional diet. Which include eight questions; 1) Do you eat meat or chicken at least 2-3 times per week. 2) Do you eat at least 5-7 portions of fruit and vegetables per day? 3) Do you eat fish at least 1-2 times per week? 4) Do you consume dairy products (milk, cheese, yoghurt) every day? 5) Do you eat whole grain carbohydrate foods (brown bread, brown pasta, brown rice or other) at least once a day? 6) Do you consume packaged snacks, cakes, pastries or sugarsweetened drinks less than five times a week? 7) Are you taking folate/folic acid, iron and calcium supplements. 8) Do you get regular exposure to the sun? Healthy diet if all answer is yes; otherwise, it is a poor diet

Ethical approval obtained from King Abdulaziz University IRB and the methods carried out in "accordance" with the approved guidelines. Authors have no conflict of interests, and the work not supported, or funded by any drug company.

Statistical analysis

The Statistical Package for the Social Sciences (SPSS Inc., Chicago, IL, USA), version 20.0 used to analyze data using chi-square test. The frequency of occurrence of different variables calculated $P$ Value less than 0.05 . Odds ratio and
95\% confidence limits used.

\section{Results}

The total number of patients selected was 210 , and only 187 questionnaires were ready for analysis the positive response rate was only $(89.1 \%)$. Their mean \pm stander deviation of age were $(28.79 \pm 5.418)$, and Gravidity $(2.98 \pm$ 2.180), Gestational Age $(29.42 \pm 7.920)$. The average hemoglobin $(9.79 \pm 1.49)$, and BMI range from $14-45$ with a mean of $(27.33 \pm 6.59)$. Table 1 .

Table 1. Baseline Characteristics.

\begin{tabular}{lllll}
\hline & Minimum & Maximum & Mean & St.Dev. \\
\hline Age & 19 & 41 & 28.79 & 5.418 \\
Gravidity & 1 & 12 & 2.98 & 2.180 \\
Gestational age & 10 & 42 & 29.42 & 7.920 \\
BMI & 14 & 45 & 27.33 & 6.59 \\
HB & 6 & 14.20 & 9.79 & 1.491 \\
Fetal weight & 1700 & 4000 & 2857.06 & 578.97 \\
\hline
\end{tabular}

Age $=$ in years; Gestational age $=$ in weeks; BMI = Body mass index; $\mathrm{HB}=$ hemoglobin gm/dL; Fetal weight $=$ in gram; Std. = stander deviation

When analyzing the questionnaires pregnant women divided into two group. Group 1 (171) those women who consumes healthy diet (eight questions answered yes) and Group 2 only 16 pregnant women out 187 (8.56\%) consumes a poor diet this according to our indicator. (Limitation that the questionnaire does not reflect the women who are eating too much because the portion size is not included only the type of food). The number of pregnant women and their gestational age at the time of the questionnaire. Table 2.

Table 2. Gestational age in weeks the number of pregnant women and their gestational age at the time of the questionnaire.

\begin{tabular}{lll}
\hline Gestational age & Frequency & Percentage \\
\hline$<28$ & 72 & 38.5 \\
$28-32$ & 41 & 21.9 \\
$32-36$ & 33 & 17.6 \\
$>36$ & 41 & 21.9 \\
Total & 187 & 100 \\
\hline
\end{tabular}

Gestational age $=$ in weeks

When the two groups compared in an age in years, gravidity, Gestational Age and BMI there was no statistically significant difference in all except in the level of hemoglobin in $\mathrm{mg} / \mathrm{dL}$ it was with statistically significant difference with a p-value $<0.017$. Table 3 .

Table 3. Compering the mean of patients characteristic in Group 1 a healthy diet and Group 2 poor diet.

\begin{tabular}{llll}
\hline & Healthy diet N=171 (Mean \pm std.dev $)$ & Poor N=16 (Mean \pm std.dev ) & p \\
\hline Age & $(28.77 \pm 5.56)$ & $(29.00 \pm 3.87)$ & $<0.87$ \\
Gravidity & $(2.93 \pm 2.12)$ & $(3.50 \pm 2.73)$ & $<0.32$ \\
Gestational age & $(29.31 \pm 7.87)$ & $(30.56 \pm 8.43)$ & $<0.55$ \\
BMI & $(27.26 \pm 1.50)$ & $(28.11 \pm 7.44)$ & $<0.62$ \\
Hemoglobin & $(9.87 \pm 1.49)$ & $(8.94 \pm 1.23)$ & $<0.017$ \\
\hline
\end{tabular}

Age = in years; Gestational age $=$ in weeks; BMI = Body mass index; Hemoglobin $=$ in gm $/$ dL; Fetal weight $=$ in gram; $\mathrm{N}=$ number; Std. $=$ stander deviation; $P$ value $=<0.05$ (Statistically Significant) 
Out of 187,48 patients $(25.7 \%)$ their hemoglobin was less than $9 \mathrm{mg} / \mathrm{dL}$, and when we compare the level of $\mathrm{Hb}$, in women consuming healthy diet with those with poor diet, there was statistically significant with $p<0.04$. Then we found that the fetal weight recorded after delivery with a (mean \pm stander deviation) (2857.06 \pm 578.97$)$. In table 4 show in comparison fetal weight in gram in both group the poor diet has more small baby which was statistically significant with $\mathrm{P}<0.026$. Table 4

Table 4. The level of hemoglobin and fetal weight in both group.

\begin{tabular}{|c|c|c|c|c|c|}
\hline Variable & Number & Percentage & Healthy diet & Poor diet & $\mathbf{P}$ \\
\hline \multicolumn{6}{|c|}{ Hemoglobin (gm/dL) } \\
\hline$>10$ & 97 & 51.9 & 93 & 4 & $<0.040^{*}$ \\
\hline $10-9$ & 42 & 22.5 & 38 & 4 & \\
\hline $9-8$ & 32 & 17.1 & 25 & 7 & \\
\hline $8-7$ & 13 & 7.0 & 12 & 1 & \\
\hline$<7$ & 3 & 1.6 & 3 & 0 & \\
\hline \multicolumn{6}{|c|}{ Fetal weight (gram) } \\
\hline$>4000$ & 11 & 5.9 & 10 & 1 & $<0.026^{*}$ \\
\hline $4000-3500$ & 23 & 12.3 & 21 & 2 & \\
\hline $3500-3000$ & 56 & 29.9 & 55 & 1 & \\
\hline $3000-2500$ & 36 & 19.3 & 35 & 1 & \\
\hline $2500-2000$ & 58 & 31 & 48 & 10 & \\
\hline$<2000$ & 3 & 1.5 & 2 & 1 & \\
\hline Total & 187 & 100 & 171 & 16 & \\
\hline
\end{tabular}

$\mathrm{P}$ value $=<0.05$ (Statistically Significant $) ;(*)=($ Statistically Significant $)$

Risk factor for poor nutrition such as age $>35$ years, primigravida, low level of education, positive medical, surgical and social history, none of this factor found to affect the frequency of food indicating that they a have a good nutritional diet Table 5 .

Table 5. Comparing both group in regard age $>35$, gravidity, educational level.

\begin{tabular}{|c|c|c|c|c|}
\hline Variable & Healthy diet $N$ (171) & Poor Diet N (16) & O. R 95\% confidence limit (lower - upper ) & $\mathbf{P}$ \\
\hline \multicolumn{5}{|l|}{ Age } \\
\hline$<35$ & 144 & 15 & $0.356(0.045-2.805)$ & 0.272 \\
\hline$>35$ & 27 & 1 & & \\
\hline \multicolumn{5}{|l|}{ Gravida } \\
\hline Primi & 48 & 3 & $1.691(0.461-6.198)$ & 0.317 \\
\hline multi & 123 & 13 & & \\
\hline \multicolumn{5}{|l|}{ Educational } \\
\hline$<$ high school & 66 & 6 & $1.048(0.364-3.018)$ & 0.579 \\
\hline More & 105 & 10 & & \\
\hline \multicolumn{5}{|c|}{ Medical history } \\
\hline No & 141 & 14 & $0.671(0.145-3.1100$ & 0.461 \\
\hline Yes & 30 & 2 & & \\
\hline \multicolumn{5}{|c|}{ Surgical history } \\
\hline No & 96 & 10 & $0.768(0.267-2.208)$ & 0.414 \\
\hline Yes & 75 & 6 & & \\
\hline \multicolumn{5}{|l|}{ Smokers } \\
\hline No & 139 & 13 & $1.002(0.270-3.726)$ & 0.608 \\
\hline Yes & 32 & 3 & & \\
\hline
\end{tabular}

$\mathrm{N}=$ number; Std. $=$ stander deviation; $\mathrm{P}$ value $=<0.05$ (Statistically Significant); O. R = odds ratio $95 \%$ confidence limit (lower - upper); Primi $=$ primgravida; Multi $=$ multigravida 
When to compare the two groups regarding the supplement there was no statistically significant difference in the two-group. Table 6.

Table 6. The use of micronutrients (folic acids, iron and calcium) in both group.

\begin{tabular}{|c|c|c|c|c|}
\hline Variable & Healthy diet N (171) & Poor Diet N (16) & O.R 95\% confidence limit (lower - upper ) & $\mathbf{P}$ \\
\hline \multicolumn{5}{|l|}{ Folic acids } \\
\hline No & 12 & 1 & $1.132(0.138-9.315)$ & 0.693 \\
\hline Yes & 159 & 15 & & \\
\hline \multicolumn{5}{|l|}{$\mathrm{Fe}++$} \\
\hline No & 30 & 4 & $0.638(0.193-2.115)$ & 0.326 \\
\hline Yes & 141 & 12 & & \\
\hline \multicolumn{5}{|l|}{$\mathrm{Ca}++$} \\
\hline No & 29 & 4 & $0.613(0.185-2.034)$ & 0.305 \\
\hline Yes & 142 & 12 & & \\
\hline
\end{tabular}

$\mathrm{N}=$ number; Std. = stander deviation; P value $=<0.05$ (Statistically Significant); O. R = odds ratio 95\% confidence limit (lower - upper); Fe $++=$ iron supplement; $\mathrm{Ca}++=$ Calcium supplement

Comparing the two groups the fetal complication were statistically significant higher in the poor diet group, with a $\mathrm{p}$ value $<0.004$ with $\mathrm{OD}$ ratio $95 \%$ confidence limit 7.318 (2.128-25.166). The level of hemoglobin were less than 10 $\mathrm{mg} / \mathrm{dL} 0.280(0.087-0.902) \mathrm{P}<0.022$. The MBI less than 25 with ODs ratio and $95 \% \mathrm{cl} 0.364(0.121-1.092)$ and $\mathrm{p}<$ 0.54. Table 7

Table 7. Comparing maternal, fetal complications-fetal wight-hemoglobin and BMI.

\begin{tabular}{|c|c|c|c|c|}
\hline Variable & Ideal diet N (171) & Poor Diet N (16) & O. R 95\% confidence limit (lower - upper ) & $\mathbf{P}$ \\
\hline \multicolumn{5}{|c|}{ Maternal complication } \\
\hline No & 126 & 12 & $0.933(0.286-3.042)$ & 0.587 \\
\hline Yes & 45 & 4 & & \\
\hline \multicolumn{5}{|c|}{ Fetal complication } \\
\hline No & 161 & 11 & $7.318(2.128-25.166)$ & $0.004 *$ \\
\hline Yes & 10 & 5 & & \\
\hline \multicolumn{5}{|c|}{ Fetal weight } \\
\hline$>2500$ & 114 & 5 & & \\
\hline \multicolumn{5}{|c|}{ Hemoglobin } \\
\hline$<10$ & 78 & 12 & $0.280(0.087-0.902)$ & $0.022 *$ \\
\hline$>10$ & 93 & 4 & & \\
\hline \multicolumn{5}{|l|}{ BMI } \\
\hline$<25$ & 76 & 11 & $0.364(0.121-1.092)$ & $0.050 *$ \\
\hline$>25$ & 95 & 5 & & \\
\hline
\end{tabular}

$P$ value $=<0.05$ (Statistically Significant)

$(*)=($ Statistically Significant $)$

\section{Discussion}

Poor Nutrition means a diet with an imbalance or insufficient food intake such as one of the components is not present, Healthy Nutrition means a diet with a well-balanced food that provides all essential nutrients necessary for growth, function, and health [5]. Healthy nutrition for women before and during pregnancy can influence pregnancy outcomes, including fetal growth restriction, diabetes, hypertension, and preterm delivery. [6].

In our study, we consider a healthy balance diet when pregnant women are enjoying fruits and vegetables of different types at least 5-7 types/day. [7]. Whole grain carbohydrate foods (brown bread, brown pasta, brown rice or other), a whole grain and high fiber options at least once a day [8].. Choosing foods that are high in iron, essential for pregnant women such as eating meat or chicken at least 2-3 times per week, fish at least 1-2 times per week [9]. [10]. [11]. Consume products (milk, cheese, yoghurt) every day, making a habit of drinking milk, and eating hard cheese and yoghurt, or calcium-enriched alternatives. Reduced-fat varieties are best. [12].. Drinking more than $1000 \mathrm{ml}$ of water per day)[13].. Snacks, cakes, pastries or sugar-sweetened drinks which high in saturated fat should be used less than five times a week and it is not a necessary part of a healthy diet and should be limited. [14].

In Mexico, $20.6 \%$ of pregnant women suffer from anemia [15]., in another study out of the 305 pregnant registered women with iron deficiency anaemia most women were young $170(55.73 \%)$ between $20-30$ years. [16]. In our study $25.7 \%$ of pregnant women their hemoglobin were less than 9 /dL. According to the WHO'S, iron and folic acid are recommended to reduce the risk of iron deficiency anemia, which is prevalent among pregnant ladies [17]. Fetal birth weight is directly proportional to maternal health and nutritional status. As a result, birth weight is an important determinant of the newborn survival, healthy growth and development. 
Accordingly, reduced fetal growth has been related to maternal under nutrition. On 2009 Kapil found that about $22 \%$ of babies born in India are born with low birth weight. [18]. In our study $32.5 \%$ their weight less than $2500 \mathrm{gm}$. Mother's age, mother's education, or husband's education were not associated with any of the food habits during pregnancy. Given the importance of nutritional value and composition of foods consumed during pregnancy and lactation, health workers should use these findings to provide appropriate nutrition counseling and education. [19]. It was found that there is a relation between dietary patterns during pregnancy and postpartum depression and that more consumption of fish, dairy olive oil and fruit \& vegetables. Also, there was some evidence showing the decrease in upper respiratory tract infection among pregnant women. [20] [21] [22]. The variety of food or diet did not differ according to occupation or income in a group of the Japanese family, the mother's iron status reflect on her newborn infant iron status and growth. health education and distribution of knowledge regarding healthy balance diet during pregnancy and Peripartum may help eliminate myths and avoid of individual dietary components. [23] [24] [25] [16].

\section{Conclusion}

In our sample of Saudi pregnant women only $8.56 \%$, and $25.7 \%$ their hemoglobin were less than $9 \mathrm{gm} / \mathrm{dL}$ and their BMI were 27. 33. Poor diet affect only the level of hemoglobin and fetal weight at delivery

\section{References}

[1] Grieger, J. \& Clifton, V., 2014. A Review of the Impact of Dietary Intakes in Human Pregnancy on Infant Birthweight. Nutrients, 7 (1), pp. 153-178.

[2] Ng, S. W. et al., 2011. Nutrition transition in the United Arab Emirates. European Journal of Clinical Nutrition, 65 (12), pp. $1328-1337$.

[3] Walsh, J. M. \& Mcauliffe, F. M., 2015. Impact of maternal nutrition on pregnancy outcome - Does it matter what pregnant women eat? Best Practice \& Research Clinical Obstetrics \& Gynaecology, 29 (1), pp. 63-78.

[4] Kelishadi, R., Mansourian, M. \& Akbari, Z., 2015. Relationship of the intake of different food groups by pregnant mothers with the birth weight and gestational age: Need for public and individual educational programs. Journal of Education and Health Promotion, 4 (1), p. 23.

[5] Keenan, K. et al., 2013. Poor nutrition during pregnancy and lactation negatively affects neurodevelopment of the offspring: evidence from a translational primate model. American Journal of Clinical Nutrition, 98 (2), pp. 396-402.

[6] Hankey, C. R., 2015. Importance of good health and nutrition before and during pregnancy. Early years nutrition and healthy weight Stewart/Early years nutrition and healthy weight, pp. $1-13$.
[7] Slavin, J. L. \& Lloyd, B., 2012. Health Benefits of Fruits and Vegetables. Advances in Nutrition: An International Review Journal, 3 (4), pp. 506-516.

[8] Skerrett, P. J. \& Willett, W. C., 2010. Essentials of Healthy Eating: A Guide. Journal of Midwifery \& Women's Health, 55 (6), pp. 492-501.

[9] Wenstrom, K. D., 2014. The FDA's new advice on fish: it's complicated. American Journal of Obstetrics and Gynecology, $211(5)$.

[10] Emmett, P. M., Jones, L. R. \& Golding, J., 2015. Pregnancy diet and associated outcomes in the Avon Longitudinal Study of Parents and Children. Nutr Rev Nutrition Reviews, 73 (suppl 3), pp. 154-174.

[11] Geissler, C. \& Singh, M., 2011. Iron, Meat and Health. Nutrients, 3 (12), pp. 283-316.

[12] Alman, B. L. et al., 2016. Associations between Maternal Water Consumption and Birth Defects in the National Birth Defects Prevention Study (2000-2005). Birth Defects Research Part A: Clinical and Molecular Teratology.

[13] Castro, M. B. T. D. et al., 2016. High cholesterol dietary intake during pregnancy is associated with large for gestational age in a sample of low-income women of Rio de Janeiro, Brazil. Maternal \& Child Nutrition.

[14] Khoushabi F, Saraswathi G. Association Between Maternal Nutrition Status and Birth Weight of Neonates in Selected Hospitals in Mysore City, India. Pakistan Journal of Nutrition. 2010 Jan; 9 (12): 1124-30.

[15] Shamah-Levy, T. et al., 2003. Anemia in Mexican women: a public health problem. Salud Pública de México, 45, pp. 499507.

[16] Khaskheli, M. et al., 2016. Iron deficiency anaemia is still a major killer of pregnant women. Pakistan Journal of Medical Sciences Pak J Med Sci, 32 (3).

[17] Zerfu, T. A. \& Ayele, H. T., 2013. Micronutrients and pregnancy; effect of supplementation on pregnancy and pregnancy outcomes: a systematic review. Nutrition Journal Nutr J, 12 (1).

[18] Kapil, U., 2009. Multiple micronutrient supplements will not reduce incidence of low birthweight. Indian Journal of Community Medicine, 34 (2), p. 85.

[19] Farahat, M. F., El-Shafie, M. M. \& Waly, M. I., 2015. Food safety knowledge and practices among Saudi women. Food Control, 47, pp. 427-435.

[20] Okubo, H. et al., 2010. Dietary patterns during pregnancy and the risk of postpartum depression in Japan: the Osaka Maternal and Child Health Study. British Journal of Nutrition, 105 (08), pp. 1251-1257.

[21] Murakami, K. et al., 2009. Education, but not occupation or household income, is positively related to favorable dietary intake patterns in pregnant Japanese women: the Osaka Maternal and Child Health Study. Nutrition Research, 29 (3), pp. 164-172.

[22] Li, L. \& Werler, M. M., 2009. Fruit and vegetable intake and risk of upper respiratory tract infection in pregnant women. Public Health Nutrition, 13 (02), p. 276. 
[23] Taha, A. et al., 2014. Iron Deficiency Anaemia In Reproductive Age Women Attending Obstetrics And Gynecology Outpatient Of University Health Centre In AlAhsa, Saudi Arabia. African Journal of Traditional, Complementary and Alternative Medicines, 11 (2), p. 339.

[24] Saadia, Z. et al., 2012. Dietary practices of Saudi women during puerperium. Journal of Obstetrics and Gynaecology Research, 39 (4), pp. 799-805.
[25] Wyness, L., 2011. Diet during pregnancy can lead to obesity in offspring. Nutrition Bulletin, 36 (3), pp. 367-369.

[26] Vézina-Im, L.-A. et al., 2016. Validity and reliability of a brief self-reported questionnaire assessing fruit and vegetable consumption among pregnant women. BMC Public Health, 16 (1). 